\title{
Exploring Confidence Levels of Pre-Service Teachers in Physical Education Field Experiences
}

\author{
Laura Brown \\ Associate Professor, Health and Human Performance \\ The University of Tennessee at Martin \\ Martin, Tennessee \\ Becky J. Cox \\ Associate Professor, Educational Studies \\ The University of Tennessee at Martin \\ Martin, TN
}

Received: August 6, 2014 Accepted: Sep. 19, 2014 Published: November 1, 2014

doi:10.5296/jse.v4i4.6311 URL: http://dx.doi.org/10.5296/jse.v4i4.6311

\begin{abstract}
The confidence levels of pre-service teachers have an impact on how effective they will be in a classroom setting. The purpose of this study is to examine the confidence levels of 16 pre-service teachers while teaching physical education and health. The college students were enrolled in a college clinical site field experience course and were placed with cooperating teachers of primary and elementary aged students. An Institutional Review Board-approved pre-test and post-test survey focused on three main confidence based statements: a) I am confident I can handle inappropriate behavior professionally, (b) I am confident with my classroom management skills and (c) I am confident I will make effective use of all class time. Using a repeated measure analysis of variance, results indicated significance on all three items at the .05 level.
\end{abstract}

Keywords: Confidence levels, Pre-service teachers, Field experience 


\section{Exploring Confidence Levels of Pre-Service Teachers in Physical Education Field Experiences}

College students preparing to be teachers traditionally spend at least one semester completing student teaching. The typical experience allows the pre-service teacher to first observe an experienced teacher with his or her classroom of students, then to fully assume the complete teaching responsibilities of the classroom. Prior to the student teaching experience, pre-service teachers participate in field experiences related to specific college coursework. Therefore, physical education pre-service teachers complete field experiences focused on developing an effective physical education classroom.

As students complete general education requirements and college coursework and begin education coursework, they begin to identify with the role of a teacher. Placing pre-service teachers in a classroom setting allows college students an opportunity to spend time in the classroom before the student teaching semester and the end of their college career. Pre-service teachers come into the teacher education program with a variety of backgrounds and capabilities. One of the differing disposition areas of pre-service teachers is confidence levels. Pre-service teachers are concerned with managing a classroom effectively and being able to handle inappropriate behavior.

\section{Literature Review}

The importance of pre-service teachers participating in field experiences prior to student teaching is well documented in the research literature. For example, results from a study conducted by Azzarito, Solomon and Afeman (2003) indicated that “(a) we learn by doing; (b) real world experiences give meaning to lectures; and (c) exchanging ideas is a powerful process" (p. A-36). Further research indicates the effects that student teaching can have on pre-service teachers. Lee and Ravizza (2008) stated that prospective teachers are allowed an opportunity to create a caring atmosphere while working with students. Additionally, this sense of caring should be developed and nurtured by both the cooperating teacher and the college instructor in order for substantial growth to take place within the pre-service teacher.

Ma, Lai, Williams, Prejean, and Ford (2008) further strengthened the link between field experience programs and teaching effectiveness. They state that teacher candidates need more interaction with children instead of merely observing the children. Ma et al. (2008) also mentioned that through more examples and practice, pre-service teachers will become automatic in making classroom-related decisions. This personal interaction allows pre-service teachers to develop an increased awareness and attentiveness to the various types of distractions that may take place within the course of a normal school day. Additionally, they will learn how to prevent and respond to these classroom management situations. A variety of factors related to early field experiences have also been explored including self-efficacy (Chase, Lirgg, \& Sakelos, 2003), types of feedback (Byra \& Marks, 1991), and assessment strategies and reflection skills (Flores-Marti, 2008).

Classroom management is a major concern for new teachers. Todorovich (2009) concluded the most prominent theme in his study of pre-service teachers was that they were anxious 
about maintaining classroom management. He found many pre-service teachers believed that students would learn best in a well-controlled classroom where the teacher provided most of the knowledge. You (2011) stated that a major factor in teaching expertise is Pedagogical Content Knowledge (PCK). PCK is based on the concept that there is much more to student learning than receiving information and more to teaching than just sharing content information to students. With the aid of beneficial experience provided by clinical classes, pre-service teachers should increase their levels of confidence. Ultimately, more time spent in the classroom will allow pre-service teachers additional opportunities to have learning situations presented to them. Ma et al. (2008) noted that the decisions teachers make daily are based on their own personal, previous experiences. The more experiences the pre-service teachers have, the better prepared they will be to teach effectively. Although student teaching usually only encompasses one semester, Ma et al. (2008) believe that the experiences and actions taken during this short timeframe will reap many dividends in their future occupational endeavors.

King (2008) writes that feedback and reflection are vital to teacher behavior; in addition it is crucial that teacher education programs provide students with feedback as an integral part of their curriculum. King (2008) states that "it is recommended that teacher educators include visual feedback or peer-generated feedback to inspire critical reflection in their students” (p. 21). Both the teacher educator and pre-service teachers benefit from feedback. The educator can discover an alternative way to share teaching methods, and the candidate is able to practice learned theories in a real-life situation. However, the investigation of confidence levels appears to have been given only minor consideration. Moreover, it is usually assumed that the confidence level of a pre-service teacher can have a major impact on the quality of the lesson and the delivery of material.

\section{Purpose of the Study}

The purpose of this study is to examine the confidence levels of 16 pre-service teachers enrolled in the department of Health and Human Performance (HHP) at a state university in the southeastern United States. The college students were enrolled in a college clinical site field experience course and were placed with cooperating teachers of primary and elementary aged students. This paper examines the confidence levels of the pre-service teachers using a pre-test survey before their field experience and a post-test survey after the field experience completion. The idea for this study came from the instructor's desire to determine at what point in the clinical experience pre-service teachers believe they are confident in their teaching skills.

\section{Method}

Participants in the study include 16 HHP pre-service teachers, cooperating teachers at local primary and elementary schools, and their assigned students. The 16 HHP College students involved were enrolled in the course Clinical Classroom I. The students were mostly sophomores and juniors. This 15-week class is the first course allowing health and physical education pre-service teachers to actually go into the public schools and interact with students. The beginning weeks of the course were held on the college campus, where students learned 
to prepare developmentally appropriate lessons. Pre-service teachers created physical education and health lessons derived from National Association of Sport and Physical Education (NASPE) guidelines and curriculum state standards. The college professor taught skills for soccer, football, fitness, Frisbee, throwing and catching, and basketball. The pre-service teachers learned to incorporate skills for these sports into their lesson plans. The college professor provided guidance on the sport skills that were to be taught; additionally, pre-service teachers were taught how to manage a classroom of approximately 20 elementary students. Other areas taught in the course work include the necessity of being prompt at the field experience site; adherence to the school dress code; and how to maintain professionalism while participating in clinical experiences. Pairs of HHP students selected a specific area of focus. It was then their responsibility to gather materials for lessons to teach their assigned students.

After the basic classroom instruction, pre-service teachers completed a confidence survey. The pre-test was administered after all lectures had been presented and pre-service students had completed practice teaching sessions using their peers as students. The post-test was administered at the conclusion of the semester, when the pre-service teachers had completed the 10 week rotation at both primary and elementary schools.

During a school orientation visit, pre-service teachers were given the opportunity to meet their assigned cooperating teacher and ask questions. Due to the abundance of information that pre-service teachers must attain from the classroom teacher, the college students conducted a short interview. This demographic information helped the pre-service teachers better understand the students they were assigned to teach.

\section{Interview Questions for Cooperating Teachers}

1. How many students are in your classroom?

2. May I have a list of names?

3. Does the school have specific guidelines concerning temperature/weather and when children may not be outdoors? If so, what are guidelines?

4. Due to "Safe School Acts" all outside doors are to remain locked at all times. Therefore, what are the bathroom procedures for your students?

5. Will you personally be outdoors with a key to let us inside the building if the need arises?

6. Are there specific rules followed by rewards or consequences?

7. What forms of technology do you use in your classroom?

\section{Procedures}

The pre-service teachers were assigned to teach two 30-minute sessions on Monday and two on Wednesday for a ten week period, divided between a primary and an elementary school. They taught first and second grade students at the primary school and fourth and fifth grade students at the elementary school. Each pair of pre-service teachers was to take charge of the 
assigned classroom and to exemplify positive leadership characteristics, while maintaining an environment conducive to learning. Pre-service teachers were to demonstrate full responsibility, as if he or she was a school employee, while on school grounds. During the lessons, pre-service teachers took the responsibility of ensuring that all students were involved and stayed on task by following classroom rules and school policies. The college professor was present at the sessions when pre-service teachers were teaching. If the instructor was not able to be in attendance at the local school, class was cancelled.

\section{Pre-Service Teacher Confidence Survey}

The instrument used to determine pre-service teachers' confidence levels used a five-point Likert scale consisting of 16 questions related to instructor identified common concerns that occur during clinical experiences (Appendix A). For the purpose of this paper three questions were chosen including: I am confident...I can handle inappropriate behavior professionally, I am confident... with my classroom management skills, and I am confident... I will make effective use of all class time. Sixteen pre-service teachers from Clinical Classroom I, the first university class in a series with field experience, participated in the pre-test and post-est. Institutional Review Board approval was attained for this study; all students volunteered to participate and all signed informed consent forms. Repeated measure analysis of variance was performed to determine confidence levels from trial to trial.

\section{Findings}

Pre-service teachers' confidence levels were examined through the survey. Three questions were specifically reviewed for the purpose of this article:

Pre-Service Teacher Confidence Survey

8. I am confident ... I can handle inappropriate behavior professionally

2. I am confident ... with my classroom management skills

9. I am confident ... I will make effective use of all class time

A repeated measure analysis of variance was performed to determine differences from trial to trial. Descriptive statistics were run to identify the mean and standard deviation regarding pre-post confidence levels for being able to handle inappropriate behavior professionally $(\mathrm{N}=16)$. The pre-test for handle inappropriate behavior professionally computed mean was 4.0625 (SD=.92871) compared to the post-test mean of 4.7500 (SD=.44721). Results determined that there was a significant difference $(F=7.348, p=.016)$ from trial to trial at the $p<.05$ level from the group as a whole.

A repeated measure analysis of variance was performed to determine differences from trial to trial for management skills. Descriptive statistics were run to identify the mean and standard deviation regarding pre-post confidence levels for classroom management skills $(\mathrm{N}=16)$. The pre-test for classroom management skills computed mean was 4.0625 (SD=.68007) compared to the post-test mean of $4.5000(\mathrm{SD}=.63246)$. Results determined that there was a significant 
difference ( $F=5.787, p=.029$ ) from trial to trial at the $p<.05$ level from the group as a whole.

Repeated measure analysis of variance was performed to determine differences from trial to trial. Descriptive statistics were run to identify the mean and standard deviation regarding pre-post confidence levels for effective use of class time $(\mathrm{N}=16)$. The pre-test for effective use of class time computed mean was 4.0625 ( $\mathrm{SD}=.92871)$ compared to the post-test mean of 4.6250 ( $\mathrm{SD}=.50000)$. Results determined that there was a significant difference $(F=5.448, p$ $=.034$ ) from trial to trial at the $p<.05$ level from the group as a whole.

Table 1.

\begin{tabular}{|lrcc}
\hline \multicolumn{3}{l}{ Pre-test and Post-test Scores } \\
\multicolumn{2}{l}{ Statement $\quad$ Pre-test } & Post-test & $F$ \\
8. & $4.0625(\mathrm{SD}=.92871)$ & $4.7500(\mathrm{SD}=.44721)$ & $(F=7.348, p=.016)$ \\
2. & $4.0625(\mathrm{SD}=.68007)$ & $4.5000(\mathrm{SD}=.63246)$ & $(F=5.787, p=.029)$ \\
9. & $4.0625(\mathrm{SD}=.92871)$ & $4.6250(\mathrm{SD}=.500000)$ & $(F=5.448, p=.034)$ \\
\hline
\end{tabular}

Results indicated that there was a statistically significant difference at the .05 level in prepost-test results for I am confident ... I can handle inappropriate behavior professionally, I am confident ...with my classroom management skills and I am confident ...I will make effective use of all class time.

\section{Conclusion}

The findings of this study are significant for the field of physical education and health as well as all pre-service teaching programs. The results identify that the clinical classroom experience is vital for the confidence levels of future teachers. It is important that upon completion of a higher education degree, graduates feel that they are prepared to accept a teaching position and believe that knowledge attained during their university higher education program has provided them the experiences they need to be successful in the classroom. Due to the small number of participants, the results cannot be generalized to a larger population. Additional studies in the area of confidence will help further support the findings from this study and reinforce the importance of hands-on learning provided by clinical experiences. The increased confidence attained through interaction with children in the classroom setting justifies the importance of clinical experiences within the university curriculum

\section{References}

Azzarito, L., Solomon, M. A., \& Afeman, H. (2003). Investigating a constructivist approach in physical education: Bridging theory and practice. Research Quarterly for Exercise and Sport, 74, A-35-36. 
Byra, M. \& Marks, M. C. (1991). Pre-service teacher's planning and teaching behaviors in a clinical setting. American Education Research Association. Chicago, IL.

Chase, M. A., Lirgg, M. C., \& Sakelos, T. J. (2003). Teacher efficacy and effective teaching behaviors in physical education. Research Quarterly for Exercise and Sport, 74, A-40(2).

Flores-Marti, I. (2008). Reflection as a critical component in the preparation of teacher candidates. Strategies, 21(6), 15-18. http://dx.doi.org/10.1080/08924562.2008.10590795

King, S. (2008). Inspiring critical reflection in pre-service teachers. Physical Educator, 65(1), 21-29.

Lee, O., \& Ravizza, D. (2008). Physical education pre-service teachers' conceptions of caring. Education, 128(3), 460-472.

Ma, Y., Lai, G., Williams, D., Prejean, L., \& Ford, M. (2008). Exploring the effectiveness of a field experience program in a pedagogical laboratory: The experience of teacher candidates. Journal of Technology and Teacher Education, 16(4), 411-431.

Todorovich, J. R. (2009). Extremely ego-oriented pre-service teachers' perspectives on teaching physical education. Journal of Teaching in Physical Education, 28, 155-172.

You, J. (2011). Portraying physical education-pedagogical content knowledge for the professional learning of physical educators. Physical Educator, 68(2), 98-112. Retrieved from http://search.proquest.com/docview/912042276?accountid=29025

\section{Appendix A}

Pre-Service Teacher Confidence Survey

Name

Date

Please circle the most appropriate response to each statement.

I am confident $0 \% \quad 100 \%$

$\begin{array}{lllll}1 & 2 & 3 & 4 & 5\end{array}$

1. I feel eager to work at the public schools

$\begin{array}{lllll}1 & 2 & 3 & 4 & 5\end{array}$

2. With my classroom management skills

$\begin{array}{lllll}1 & 2 & 3 & 4 & 5\end{array}$

3. I will do well in the school setting

$\begin{array}{lllll}1 & 2 & 3 & 4 & 5\end{array}$

4. I can manage the safety of the students

$\begin{array}{lllll}1 & 2 & 3 & 4 & 5\end{array}$

5. I can handle an emergency situation

$\begin{array}{lllll}1 & 2 & 3 & 4 & 5\end{array}$

6. I can manage myself well in a classroom setting

$\begin{array}{lllll}1 & 2 & 3 & 4 & 5\end{array}$

7. I can maintain and enforce school rules

$\begin{array}{lllll}1 & 2 & 3 & 4 & 5\end{array}$




\section{Macrothink}

Journal of Studies in Education ISSN 2162-6952 2014, Vol. 4, No. 4

8. I can handle inappropriate actions professionally

9. I will make effective use of class time

10. All students will want to participate

11. I can handle negative attitudes in students

12. I can get students' attention

$\begin{array}{lllll}1 & 2 & 3 & 4 & 5\end{array}$

13. I can begin class promptly

$\begin{array}{lllll}1 & 2 & 3 & 4 & 5\end{array}$

14. I will give appropriate feedback

$\begin{array}{lllll}1 & 2 & 3 & 4 & 5\end{array}$

15. Students will like the games/activities I teach

$\begin{array}{lllll}1 & 2 & 3 & 4 & 5\end{array}$

16. I will not embarrass myself in class

$\begin{array}{lllll}1 & 2 & 3 & 4 & 5\end{array}$ 